\title{
Correction to: Glomerulosclerosis predicts poor renal outcome in patients with idiopathic membranous nephropathy
}

\author{
Cuimei Wei ${ }^{1,3}$. Yongcheng $\mathrm{He}^{2,3} \cdot$ Tong $\mathrm{Li}^{2,3} \cdot$ Haofei $\mathrm{Hu}^{2,3} \cdot$ Haiying Song ${ }^{2,3} \cdot$ Dongli $\mathrm{Qi}^{2,3} \cdot$ Yuan Cheng ${ }^{2,3}$. Jia Chen ${ }^{2,3}$. \\ Mijie Guan ${ }^{2,3} \cdot$ Xiaohua Xiao ${ }^{1,3} \cdot$ Junyi $\mathrm{Li}^{4}$
}

Published online: 28 October 2020

๑) Springer Nature B.V. 2020

\section{Correction to: International Urology and Nephrology https://doi.org/10.1007/s11255-020-02641-5}

The article 'Glomerulosclerosis predicts poor renal outcome in patients with idiopathic membranous nephropathy', written by Cuimei Wei, Yongcheng He, Tong Li, Haofei Hu, Haiying Song, Dongli Qi, Yuan Cheng, Jia Chen, Mijie Guan, Xiaohua Xiao, Junyi Li, was originally published electronically on the publisher's internet portal (currently SpringerLink) on 22 September 2020 with open access. With the author(s)' decision to step back from Open Choice, the copyright of the article changed on 25 October 2020 to (C) Springer Nature B.V. 2020 and the article is forthwith distributed under the terms of copyright.

The original article can be found online at https://doi.org/10.1007/ s11255-020-02641-5.

Tong Li

tonglidoc@126.com

1 Department of Geriatrics, The First Affiliated Hospital of Shenzhen University, No. 3002 Sungang Road, Futian, Shenzhen 518035, Guangdong, China

2 Department of Nephrology, The First Affiliated Hospital of Shenzhen University, Shenzhen 518035, Guangdong, China

3 Shenzhen Second People's Hospital, Shenzhen 518000, Guangdong, China

4 Department of Applied Statistics, School of Applied Mathematics, Guangdong University of Technology, Guangzhou 510643, China
The original article has been corrected.

Publisher's Note Springer Nature remains neutral with regard to jurisdictional claims in published maps and institutional affiliations. 